\title{
A Composite Index to Adaptively Perform Fault Detection, Classification, and Direction Discrimination for Transmission Lines
}

\author{
Joe-Air Jiang, Ching-Shan Chen, Ping-Lin Fan, Chih-Wen Liu, Member, IEEE, and Rong-Seng Chang
}

\begin{abstract}
This paper presents an adaptive protection scheme for transmission lines based on synchronized phasor measurements. The work includes: fault detection, fault classification, and fault direction discrimination. Using two-terminal synchronized measurements incorporated with distributed line model and Clarke transformation theory, fault detection index is derived. We can classify the faults by the proposed modal fault detection index and the circuit breaker can achieve single-pole tripping. The fault detection index is composed of two complex phasors. The fault events can be found according to the angle difference between these two phasors as in internal and external fault situation. The proposed method also combines on-line parameter estimation to assure protection scheme performance and to achieve adaptive protection. After a lot of EMTP simulations and verifications show that the method provides a fast and accurate protection scheme for transmission lines. The tripping decision time of protective relay is within $1 / 2$ cycle.
\end{abstract}

Index Terms - Computer Relaying, Fault Classification, Fault Detection, Fault Direction Discrimination, Global Positioning System (GPS), Phasor Measurement Unit (PMU)

\section{INTORDUCTION}

Distance relay is the common protection method used in the transmission lines. The relay setting values are usually kept constant, so the under-reach or over-reach case occurs due to the remote in-feed currents and the fault resistance. In order to improve the performance, the adaptive protection concepts are proposed [1], [2]. The distance relay acts more accurate by data transmission through communication channel to achieve relay's adaptive setting. A. A. Girgis [3] proposed the Kalman filtering technique to calculate steady-state fundamental phasor quickly, which speed up distance relay response. Recently, transmission line fault protections by means of pattern recognition through artificial neural network are proposed [4], [5]. Although the performance of those is acceptable, the neural network training is expendable and the miss-judgement rate still need to be reduced.

The method adopts parameter estimation based on lumped model and differential equation algorithm is used in distance protection [6]. Such a protection technique is not affected by

J.-A. Jiang is with Department of Bio-industrial Mechatronics Engineering, National Taiwan University, Taipei, Taiwan.

C.-S. Chen and C.-W. Liu are with Department of Electrical Engineering, National Taiwan University, Taipei, Taiwan.

B.-L. Fan and R.-S Chang are with Institute of Optics Science, National Central University, Chung-Li, Taiwan.
DC offset and possesses good relaying responsibility. Because of neglecting the line charging currents, this method is only suitable for short distance.

The traveling wave based algorithm is proposed to eliminate fault rapidly and reinforce the system stability [1], [7]. But the high sampling rate and the bandwidth limit of CT and CCVT decrease accuracy. Recently, the transient-based protection is proposed [8]. This method utilizes the fault-generated signals that are produced during arcing and the associated high frequency signals are synchronized with Global Positioning System. This completes the transmission line protection and location without the drawback of the traveling wave based algorithm. Because of the speedy response, the high sampling rate with specified tank is designed to gather high frequency signals.

The line current differential relay is easy to be realized to protect the whole transmission line. As applied in the long transmission line, the relay setting values are difficult to be decided due to the line charging current and the unobvious current variation during high impedance fault. The composite voltage and current measurements are used to reinforce relay sensitivity and to improve the performance [9].

By means of GPS and the fiber optic communication system, high accuracy and speedy data transmission can be achieved. Better protection and location performance can be achieved by two end measurements to complete transmission line protection [8]-[12]. Based on our previous work [11], [12], this paper utilizes synchronized phasor measurements to design a multi-function protection relay to reach the whole line protection. This provides the speedy, robust, and accurate fault detection and discrimination ability.

\section{BASIC PRINCIPLES}

Based on the proposed method [11], [12], we review the principle of the fault detection first. By means of the modal fault detection index, the fault types identification is achieved. The internal and external fault discriminations are also discussed.

\section{A. Fault Detection}

Consider a single-circuit transposed transmission line case. By two terminal synchronized phasor measurements and distributed line model; the authors utilize Clarke transform to decouple the inter-phase effect of transmission line. The voltages at fault point $\mathrm{F}$ (locates at $\mathrm{x}=\mathrm{DL} \mathrm{km}$ away from a receiving end, $\mathrm{D}$ is the per unit length, and $\mathrm{L}$ is the total 
length of the protected transmission line) and $\mathrm{x}=0$ are taken as boundary conditions [11]. The fault detection index is therefore solved as followings:

$$
\begin{aligned}
\mathrm{M}_{\mathrm{m}}= & \frac{1}{2} \exp \left[-\Gamma_{\mathrm{m}} \mathrm{L}\right]\left[\mathrm{V}_{\mathrm{Sm}}+\mathrm{Z}_{\mathrm{Cm}} \mathrm{I}_{\mathrm{Sm}}\right] \quad m \equiv 0, \alpha, \beta \\
& -\frac{1}{2}\left[\mathrm{~V}_{\mathrm{Rm}}+\mathrm{Z}_{\mathrm{Cm}} \mathrm{I}_{\mathrm{Rm}}\right] \\
= & \mathrm{E}_{\mathrm{m}}-\mathrm{B}_{\mathrm{m}}
\end{aligned}
$$

where $\Gamma_{\mathrm{m}}$ represents m-mode propagation constant, $\mathrm{Z}_{\mathrm{Cm}}$ represents m-mode surge impedance, and $V_{R m}, V_{S m}, I_{R m}$, $\mathrm{I}_{\mathrm{Sm}}$ represent the synchronized m-mode measurements of receiving end/sending end voltages and currents, respectively.

In this work, the authors adopt moving-window recursive full-cycle DFT to calculate fundamental steady-state phasors. The absolute value of $\mathrm{M}_{\mathrm{m}}$ for every moving data window is held at zero before the occurrence of a fault [11]. If the moving window contains the post-fault data, then the index $\left|M_{m}\right|$ will rise with very large slope. Thus, the index $\left|M_{m}\right|$ can be used as the fault detection index. Considering the physical measurements and calculation errors, $\left|\mathrm{M}_{\mathrm{m}}\right|$ may not equal to zero under healthy status. Therefore, a threshold is needed to avoid misoperation.

\section{B. Fault Classification and Phase Selection}

The Clarke transformation method is used to do line decoupling. Not every modal component can be used to perform fault detection. With respect to different fault types, some specific modal component may fail to detect fault. The available modes under various faults are shown in the shadow area in the Table 1.

The fault classification can not directly be made from the pattern in the shadow area shown in the Table 1. In the work [7], they assumed that the basis of the transformation is phase ' $a$ ', 'b' and 'c'. Three patterns are produced by Karrenbauer transform to achieve fault classification. This method can also be applied to Wedepohl and Clarke transformations [7]. Our work is based on the Clarke transformation and collocates with the proposed fault detection index to obtain the Table 1. Based on this table, the fault classification algorithm can be obtained and shown in Fig. 1. This algorithm can be used to classify the fault types and to perform phase selection.

For the single phase grounding fault cases, according to Fig. 1, the faulted phase selection is fulfilled and then the single-pole tripping is achieved. There is a little difference in rising speed among the modal fault detection indices. For the sake of high dependability and security, only the same pattern is cumulatively twice, i.e. the fault type is completely confirmed, the proposed relaying scheme proceeds to perform next step.

\section{Fault Direction Discrimination}

The proposed fault detection index is composed of two

\begin{tabular}{|c|c|c|c|c|c|c|c|c|c|c|c|c|}
\hline \multicolumn{2}{|c|}{ Fault types } & \multicolumn{3}{|c|}{ LG } & \multicolumn{3}{|c|}{ LLS } & \multicolumn{3}{|c|}{$\overline{\mathrm{LLG}}$} & \multicolumn{2}{|c|}{$3 \mathrm{LS} / 3 \mathrm{LG}$} \\
\hline Basis & $\begin{array}{c}\text { Fault } \\
\text { detection } \\
\text { index } \\
\end{array}$ & ag & bg & $\mathrm{cg}$ & abs & bcs & cas & abg & bcg & cag & abcs & abcg \\
\hline \multirow{3}{*}{$\begin{array}{c}\text { Phase } \\
\text { a }\end{array}$} & $\left|\mathrm{M}_{0}^{\mathrm{a}}\right|$ & 1 & 1 & 1 & 0 & 0 & 0 & 1 & 1 & 1 & 0 & 0 \\
\hline & $\left|\mathrm{M}_{\alpha}^{\mathrm{a}}\right|$ & 1 & 1 & 1 & 1 & 0 & 1 & 1 & 1 & 1 & 1 & 1 \\
\hline & $\left|\mathrm{M}_{\beta}^{\mathrm{a}}\right|$ & 0 & 1 & 1 & 1 & 1 & 1 & 1 & 1 & 1 & 1 & 1 \\
\hline \multirow{3}{*}{$\begin{array}{c}\text { Phase } \\
\mathrm{b}\end{array}$} & $\left|\mathrm{M}_{0}^{\mathrm{b}}\right|$ & 1 & 1 & 1 & 0 & 0 & 0 & 1 & 1 & 1 & 0 & 0 \\
\hline & $\left|\mathrm{M}_{\alpha}^{\mathrm{b}}\right|$ & 1 & 1 & 1 & 1 & 1 & 0 & 1 & 1 & 1 & 1 & 1 \\
\hline & $\left|\mathrm{M}_{\beta}^{\mathrm{b}}\right|$ & 1 & 0 & 1 & 1 & 1 & 1 & 1 & 1 & 1 & 1 & 1 \\
\hline \multirow{3}{*}{$\begin{array}{c}\text { Phase } \\
\text { c }\end{array}$} & $\left|\mathrm{M}_{0}^{\mathrm{c}}\right|$ & 1 & 1 & 1 & 0 & 0 & 0 & 1 & 1 & 1 & 0 & 0 \\
\hline & $\left|M_{\alpha}^{c}\right|$ & 1 & 1 & 1 & 0 & 1 & 1 & 1 & 1 & 1 & 1 & 1 \\
\hline & $\left|\mathrm{M}_{\beta}^{\mathrm{c}}\right|$ & 1 & 1 & 0 & 1 & 1 & 1 & 1 & 1 & 1 & 1 & 1 \\
\hline
\end{tabular}
complex phasors. Using the angle difference between these two phasors, we can attain fault direction discrimination.
Table 1 The available modes under different transformation basis.

" 1 " represents that the index is greater than threshold and rises with a large slope.

$$
\begin{aligned}
& \text { if }\left|\mathrm{M}_{0}^{\mathrm{a}}\right|,\left|\mathrm{M}_{0}^{\mathrm{b}}\right| \text { and }\left|\mathrm{M}_{0}^{\mathrm{c}}\right|>\text { Threshold } \\
& \text { if }\left|\mathrm{M}_{\beta}^{\mathrm{a}}\right|<\text { Threshold then a-phase ground fault; } \\
& \text { else if }\left|\mathrm{M}_{\beta}^{\mathrm{b}}\right|<\text { Threshold then b-phase ground fault ; } \\
& \text { else if }\left|\mathrm{M}_{\beta}^{\mathrm{c}}\right|<\text { Threshold then c-phase ground fault ; } \\
& \text { else double phase ground fault; } \\
& \text { end } \\
& \text { else if }\left|\mathrm{M}_{\alpha}^{\mathrm{a}}\right|<\text { Threshold then } \mathrm{b} \text {-c phase short fault; } \\
& \text { else if }\left|\mathrm{M}_{\alpha}^{\mathrm{b}}\right|<\text { Threshold then c-a phase short fault; } \\
& \text { else if }\left|\mathrm{M}_{\alpha}^{\mathrm{c}}\right|<\text { Threshold then a-b phase short fault; } \\
& \text { else } \\
& \text { three-phase ground or short fault; } \\
& \text { end }
\end{aligned}
$$

Fig.1 The fault classification algorithm for transposed transmission line.

The concept is described below.

1) Internal fault case: As shown in Fig. 2, the current $I_{R}$ reverses and the available fault detection index $\left|\mathrm{M}_{\mathrm{m}}\right|$ rises rapidly with a large slope. We obtain $\left|\mathrm{E}_{\mathrm{m}}\right| \neq\left|\mathrm{B}_{\mathrm{m}}\right|$ and $\angle \theta_{\mathrm{Em}} \neq$ $\angle \theta_{\mathrm{Bm}}$, so that $\left|\mathrm{M}_{\mathrm{m}}\right| \neq 0$.

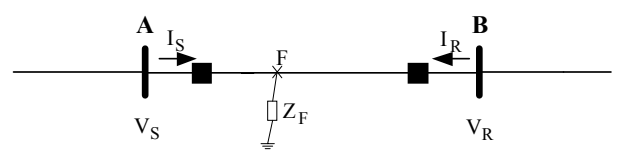

Fig. 2 Internal fault case: fault occurs between bus A and B.

2) External fault case: Suppose that the fault occurs in the right-hand side of bus B. As shown in Fig. 3, both the direction of current $\mathbf{I}_{\mathrm{S}}$ and $\mathbf{I}_{\mathrm{R}}$ is unchanged. In the steady state, we obtain $\left|\mathrm{E}_{\mathrm{m}}\right|=\left|\mathrm{B}_{\mathrm{m}}\right|$ and $\angle \theta_{\mathrm{Em}}=\angle \theta_{\mathbf{B m}}$, so that $\left|\mathrm{M}_{\mathrm{m}}\right|=$ 0 is same as the no fault case. Similarly, the scheme provides same result when fault occurs in the left-hand side of bus A. 


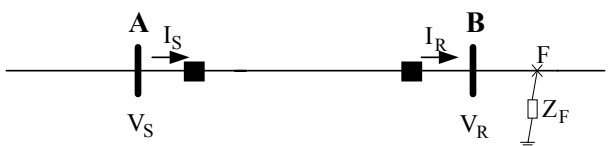

Fig. 3 External fault case: fault occurs in the right-hand side of bus B.

From the $\arg \left(\mathrm{E}_{\mathrm{m}} / \mathrm{B}_{\mathrm{m}}\right)=\arg \left(\left|\mathrm{E}_{\mathrm{m}}\right| \angle \theta_{\mathrm{Em}} /\left|\mathrm{B}_{\mathrm{m}}\right| \angle \theta_{\mathrm{Bm}}\right)=\angle \theta_{\mathrm{Em}}$ $-\angle \theta_{\mathrm{Bm}}$, the internal and external faults can be discriminated by the following criteria:

Internal fault: $\operatorname{abs}\left[\arg \left(\mathrm{E}_{\mathrm{m}} / \mathrm{B}_{\mathrm{m}}\right)\right]=\operatorname{abs}\left(\angle \theta_{\mathrm{Em}}-\angle \theta_{\mathrm{Bm}}\right) \neq 0$

External fault: $\operatorname{abs}\left[\arg \left(\mathrm{E}_{\mathrm{m}} / \mathrm{B}_{\mathrm{m}}\right)\right]=\operatorname{abs}\left(\angle \theta_{\mathrm{Em}}-\angle \theta_{\mathrm{Bm}}\right)=0$

where $\arg (\bullet)$ denotes the phase angle.

The responsibility of the discrimination criteria is rapid and sensitive when the fault happens. For an internal fault case, the absolute value of the $\arg \left(\mathrm{E}_{\mathrm{m}} / \mathrm{B}_{\mathrm{m}}\right)$ rises to a certain value with a large slope. For an external fault case, the absolute value of the $\arg \left(\mathrm{E}_{\mathrm{m}} / \mathrm{B}_{\mathrm{m}}\right)$ will fast decay to zero. Thus, from (2) and (3), we can set a threshold incorporated with a counter limit to discriminate fault zone.

\section{THE ADAPTIVE PROTECTION SCHEME}

The sampling synchronization of PMU-GSCG configuration has been verified via field tests of Taipower $161 \mathrm{kV}$ substations [12]. The configuration of the proposed adaptive protection system is shown in Fig. 4. At each substation, the relay measures the local PMU phasor and receives the synchronized phasors from the remote PMU by communication channel.

The phasor quantities are decoupled into modal components using Clarke transformation. Then, we use (1) to calculate modal fault detection index $\left|\mathrm{M}_{\mathrm{m}}\right|$. The on-line parameter estimation provides the on-line update of the line parameters at intervals of predetermined time. Hence, the variation of line parameters will not affect the performance of the protection system. The performance of on-line parameter estimation has been verified in [12].

No matter what fault zone is, the available fault detection index $\left|\mathrm{M}_{\mathrm{m}}\right|$ is greater than threshold $(\mathrm{Th}=50)$ and the fault is determined. However, for an external fault, the index $\left|\mathrm{M}_{\mathrm{m}}\right|$ will decay with time. In the internal fault cases, the index $\left|\mathrm{M}_{\mathrm{m}}\right|$ will rise to a steady value.

In the next stage, the proposed protection system first performs Clarke transformations with respect to a-, b-, and c-phase basis. Then, the algorithm shown in Fig. 1 fulfills the fault classification and phase selection. To make sure of an accurate judgement, the proposed scheme proceeds to do next step only after two cumulative same pattern confirmed.

At this stage, the available modes have been chosen. Whether the cumulative four $\arg \left(\mathrm{E}_{\mathrm{m}} / \mathrm{B}_{\mathrm{m}}\right)$ data are greater than the threshold $(0.6 \mathrm{rad})$ or not is used to distinguish internal fault from external fault. When an internal fault is determined, the protection system goes to the next step. Otherwise, the system will go back to phasor quantities decoupling stage.

Finally, the designed protection system performs a tripping

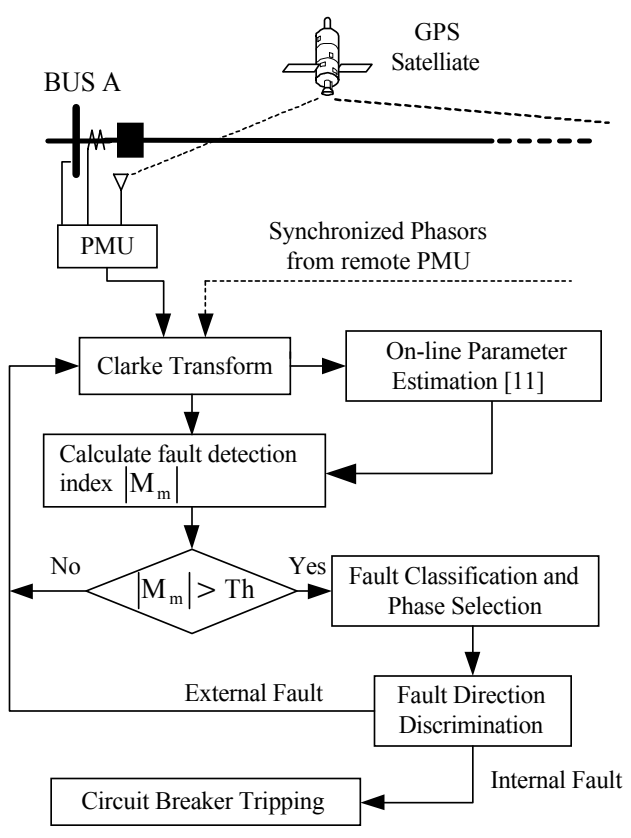

Fig. 4 The configuration of the proposed adaptive protection system.

decision strategy. When single-phase fault occurs in the protected line, the designed protection system issues a single-pole tripping signal.

\section{Performance Evaluation}

For evaluating the performance of the proposed algorithm, the authors adopt ATP version of EMTP [13] to do various fault simulations. Fig. 5 depicts the single-line diagram of the simulated system, which is a $345 \mathrm{kV}$ transposed transmission line system. Distributed line model is utilized in this simulation. $\mathrm{T} 1$ is a protected line segment. The parameters of adopted line and two Thévenin's equivalent source circuits are same as in [12]. In this work, the phase difference between $E_{S}$ and $E_{R}$ is set as 20 degrees.

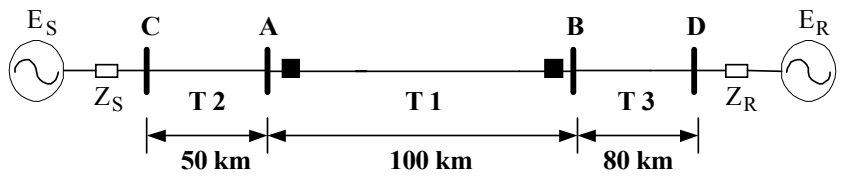

Fig. 5 The Single-line diagram of simulation system.

The sampling frequency of simulation is $1920 \mathrm{~Hz}$ (i.e. 32 samples per cycle). A second-order low-pass Butterworth pre-filter whose cutoff frequency is $300 \mathrm{~Hz}$ first filters the faulted waveforms generated by EMTP. To demonstrate the robustness of the proposed algorithm, the simulations are performed with respect to different fault conditions. In these simulations, all of the fault events occur $24 \mathrm{~ms}$. The selected simulation results are briefly summarized as follows:

\section{A. Typical Internal Fault Responses}

In this paper, we select two test cases to illustrate the performance of the proposed relaying scheme under internal fault events. 


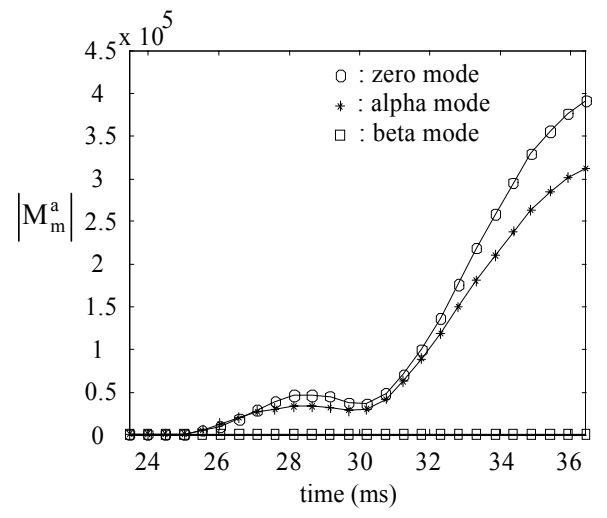

(a) basis : phase a

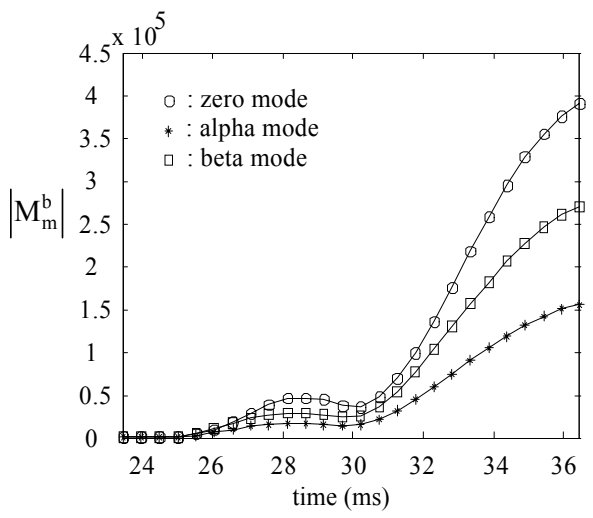

(b) basis : phase $\mathrm{b}$

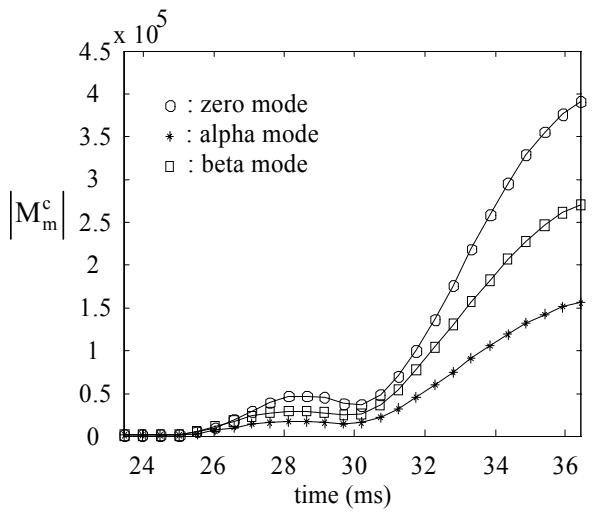

(c) basis : phase c

Fig. 6 The behaviors of fault detection index $\left|\mathrm{M}_{\mathrm{m}}\right|$ under different transformation basis.

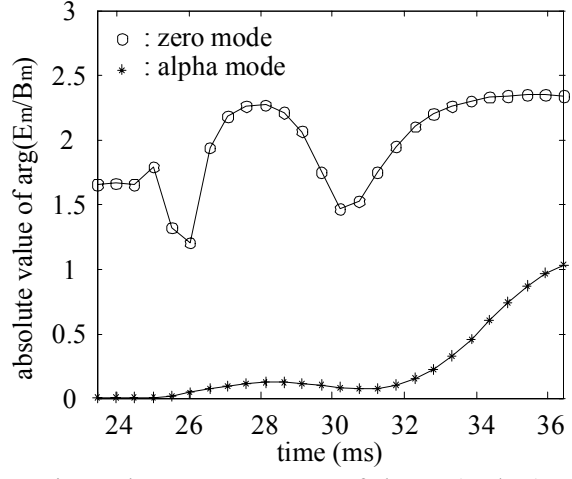

Fig. 7 The response curves of $\operatorname{abs}[\arg (\mathrm{Em} / \mathrm{Bm})]$ for Case 1 .

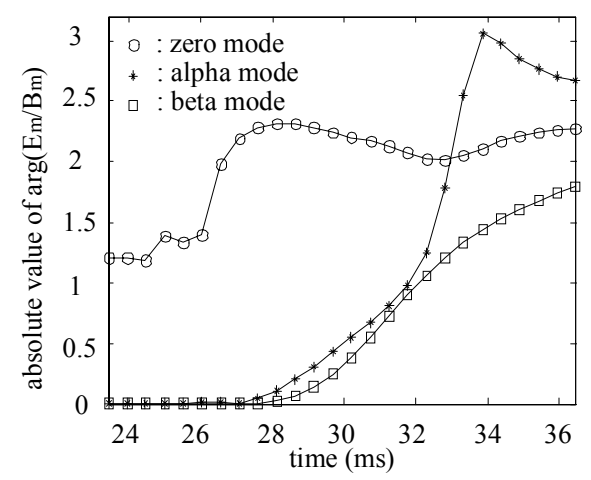

Fig. 8 The response curves of $\operatorname{abs}[\arg (\mathrm{Em} / \mathrm{Bm})]$ for Case 2.

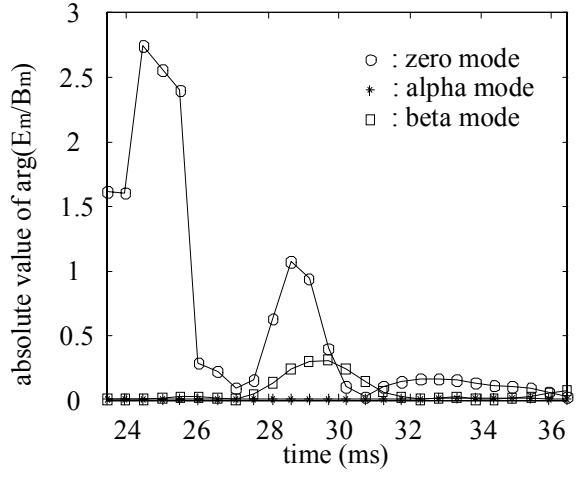

Fig. 9 The response curves of $\operatorname{abs}[\arg (\mathrm{Em} / \mathrm{Bm})]$ for external fault.
Case 1: A-phase ground fault is selected as simulation case whose fault path resistance is $1 \Omega$, fault location is at 0.4 (p.u.), and fault inception angle is $6^{\circ}$ refers to a-phase voltage wave, respectively.

Fig. 6 depicts the behaviors of modal fault detection index $\left|\mathrm{M}_{\mathrm{m}}\right|$ under different transformation basis. The threshold setting of $\left|\mathrm{M}_{\mathrm{m}}\right|$ is chosen to be 50. Fig. 6(a) indicates that $\left|\mathrm{M}_{\mathrm{m}}\right|$ value will be greater than threshold setting at the time $1.042 \mathrm{~ms}$ after fault occurrence such that the fault can be detected. Using Fig. 6(a) (c) incorporated with the fault type discrimination patterns shown in Table 1, the a-phase ground fault can be detected at the time $1.563 \mathrm{~ms}$ after fault occurrence. Fig. 7 shows the zero mode and alpha mode response curves of $\operatorname{abs}\left[\arg \left(\mathrm{E}_{\mathrm{m}} / \mathrm{B}_{\mathrm{m}}\right)\right]$. An inspection of this figure clearly observes that the post-fault angle variation of zero-mode is very fast and whose value is greater than threshold setting 0.6 (rad) in cumulative four samples. This fact implies that such an a-phase ground fault is an internal fault. In summary, the relaying scheme can achieve the task for making a tripping decision at the time $3.125 \mathrm{~ms}$ after fault occurrence.

Case 2: AB-phase ground fault is selected as simulation case whose fault path resistance is $100 \Omega$, fault location is at 0.5 (p.u.), and fault inception angle is $6^{\circ}$, respectively.

Even the fault path resistance is up to $100 \Omega$, the proposed scheme still provides excellent relaying performance. Fig. 8 shows the different modal response curves of $\left.\operatorname{absarg}\left(\mathrm{E}_{\mathrm{m}} / \mathrm{B}_{\mathrm{m}}\right)\right]$. When the time is $27.646 \mathrm{~ms}$, the zero-mode component detects this internal fault such that relay tripping decision can be made fast.

It is worthy noted that the zero modal signals $\mathrm{E}_{0}=\mathrm{B}_{0}=0$ during healthy status in the three-phase balanced system. And the $\arg \left(\mathrm{E}_{0} / \mathrm{B}_{0}\right)$ will be an uncertain value. So, the $\arg \left(\mathrm{E}_{0} / \mathrm{B}_{0}\right)$ is meaningless in the pre-fault period.

\section{B. Typical External Fault Responses}

This subsection presents the responses of the proposed scheme with respect to external fault events. The BC-phase ground fault is selected as a simulation sample, which occurs in line segment T2. The fault path resistance is $1 \Omega$ and fault location is at $10 \mathrm{~km}$ away from Bus A. Fig. 9 describes the response curves of $\operatorname{abs}\left[\arg \left(\mathrm{E}_{\mathrm{m}} / \mathrm{B}_{\mathrm{m}}\right)\right]$ under this external fault event. The value of $\operatorname{abs}\left[\arg \left(\mathrm{E}_{\mathrm{m}} / \mathrm{B}_{\mathrm{m}}\right)\right]$ will soon decay to zero. While the zero-modal component of $\operatorname{abs}\left[\arg \left(\mathrm{E}_{\mathrm{m}} / \mathrm{B}_{\mathrm{m}}\right)\right]$ may be greater than threshold setting (0.6), it is still easy to cope with this phenomenon by deliberately using a counter limit. In this work, the counter limit is chosen to be 4. Such an arrangement has verified that the proposed relaying scheme never misjudges any fault events in this study. 


\section{Statistical Evaluation for Relay Response}

\section{1) Different fault types and positions}

An extensive series of simulation studies have been carried out to examine the effects of different fault types and positions on the performance of the proposed relaying scheme. In these tests, fault inception angles are all set at 6 degrees and fault resistances are set as $1 \Omega$. From Table 2, it is clearly indicated that the proposed scheme is hardly affected by fault positions. And the response of the designed relay is very fast and stable.

Table 2 Effects of fault types and positions on the tripping decision time

\begin{tabular}{ccccc}
\hline \multirow{2}{*}{$\begin{array}{c}\text { Fault } \\
\text { positions }\end{array}$} & ag & bcg & cas & abcg \\
\cline { 2 - 5 } 0.05 (p.u.) & $3.125(\mathrm{~ms})$ & $3.125(\mathrm{~ms})$ & $5.729(\mathrm{~ms})$ & $6.250(\mathrm{~ms})$ \\
\hline 0.2 (p.u.) & $3.125(\mathrm{~ms})$ & $3.125(\mathrm{~ms})$ & $6.250(\mathrm{~ms})$ & $7.292(\mathrm{~ms})$ \\
\hline 0.5 (p.u.) & $3.125(\mathrm{~ms})$ & $3.125(\mathrm{~ms})$ & $6.250(\mathrm{~ms})$ & $7.292(\mathrm{~ms})$ \\
\hline 0.8 (p.u.) & $3.125(\mathrm{~ms})$ & $3.125(\mathrm{~ms})$ & $6.250(\mathrm{~ms})$ & $7.292(\mathrm{~ms})$ \\
\hline 0.95 (p.u.) & $3.125(\mathrm{~ms})$ & $3.125(\mathrm{~ms})$ & $6.250(\mathrm{~ms})$ & $7.292(\mathrm{~ms})$ \\
\hline
\end{tabular}

\section{2) Different fault path resistance}

The selected EMTP simulation results are shown in Table 3. In these tests, fault inception angles are all set to be $6^{\circ}$ and fault locations are intentionally selected at remote end $\mathrm{D}=0.9$ (p.u.). From the shown table, it is clearly observed that the proposed relaying technique is almost insensitive to fault path resistance. Even in the extremely case of $1000 \Omega$, the scheme still provides excellent responsibility.

Also, the performance evaluation associated with different inception angle, different source impedances and different pre-load flows have been conducted and all of the results are satisfactory.

Table 3 Effects of fault path resistance on tripping decision time

\begin{tabular}{cccc}
\hline Fault resistance & \multicolumn{3}{c}{ Fault types } \\
\cline { 2 - 4 } & $\mathrm{ag}$ & $\mathrm{abg}$ & $\mathrm{abcg}$ \\
\hline $1(\mathrm{ohm})$ & $3.646(\mathrm{~ms})$ & $3.646(\mathrm{~ms})$ & $7.292(\mathrm{~ms})$ \\
\hline $10(\mathrm{ohm})$ & $3.125(\mathrm{~ms})$ & $3.646(\mathrm{~ms})$ & $7.292(\mathrm{~ms})$ \\
\hline $100(\mathrm{ohm})$ & $3.125(\mathrm{~ms})$ & $3.646(\mathrm{~ms})$ & $7.292(\mathrm{~ms})$ \\
\hline $1000(\mathrm{ohm})$ & $3.125(\mathrm{~ms})$ & $3.646(\mathrm{~ms})$ & $7.292(\mathrm{~ms})$ \\
\hline
\end{tabular}

\section{CONCLUSION}

An adaptive PMU-based protection scheme is presented in this paper. An extensive series of EMTP simulations has demonstrated that the proposed scheme can provide excellent performance on fault detection, fault classification, and fault direction discrimination. The tripping decision time of the proposed protection scheme is very fast and stable, whose value on average is well within half a cycle. All of these functions are least sensitive to various system situations and fault events. With the advancement of digital signal processor and communication technology, the proposed scheme is very potential and competitive.

\section{REFERENCES}

[1] A. G. Phadke and J. S. Thorp, Computer Relaying for Power Systems, John Wiley \& Sons, New York, 1988.

[2] Working Group H-7 of the Relaying Channels Subcommittee of the IEEE Power System Relaying Committee, "Synchronized Sampling and Phasor Measurements for Relaying and Control", IEEE Trans. on Power Delivery, vol. 9, no. 1, January 1994, pp. 442-452.

[3] A. A. Girgis and E. B. Makram, "Application of Adaptive Kalman Filtering in Fault Classification, Distance Protection, and Fault Location Using Microprocessors", IEEE Trans. on Power Systems, Vol. 3, No. 1, February 1988, pp. 301-309.

[4] D. V. Coury and D. C. Jorge, "Artificial Neural Network Approach to Distance Protection of Transmission Lines", IEEE Trans. on Power Delivery, Vol. 13, No. 1, January 1998, pp. 102-108.

[5] T. S. Sidhu, H. Singh, and M. S. Sachdev, "Design, Implementation and Testing of An Artificial Neural Network Based Fault Direction Discriminator for Protecting Transmission Lines", IEEE Trans. on Power Delivery, Vol. 10, No. 2, April 1995, pp. 697-706.

[6] M. Akke and J. S Thorp, "Some Improvements In the Three-Phase Differential Equation Algorithm for Fast Transmission Line Protection", IEEE Trans. on Power Delivery, vol. 13, no. 1, January 1998, pp. 66-72.

[7] M. M. Mansour and G. W. Swift, "A Multi-Microprocessor Based Traveling Wave Relay - Theory and Realization", IEEE Trans. on Power Delivery, Vol. 1, No. 1, January 1986, pp. 272-279.

[8] Z. Q. Bo, G. Weller, T. Lomas, and M. A. Redfern, "Positional Protection of Transmission Systems Using Global Positioning System", IEEE Trans. on Power Delivery, Vol. 15, No. 4, October 2000, pp. 1163-1168.

[9] R. K. Aggarwal and A. T. Johns, "A Differential Line Protection Scheme for Power Systems Based On Composite Voltage and Current Measurements", IEEE Trans. on Power Delivery, Vol. 4, No. 3, July 1989, pp. 1595-1601.

[10] H. Y. Li, E. P. Southern, P. A. Crossley, S. Potts, S. D. A. Pickering, B. R. J. Caunce and G. C. Weller, "A New Type of Differential Feeder Protection Relay Using the Global Positioning System for Data Synchronization", IEEE Trans. on Power Delivery, vol. 12, no.3, July 1997, pp. 1090-1097.

[11] J. A. Jiang, J. Z. Yang, Y. H. Lin, C. W. Liu, and J. C. Ma, “An Adaptive PMU Based Fault Detection/Location Technique for Transmission Lines, Part I: Theory and Algorithms", IEEE Trans. on Power Delivery, vol. 15, no. 2, April 2000, pp. 486-493.

[12] J. A. Jiang, Y. H. Lin, J. Z. Yang, T. M. Too, C. W. Liu, "An Adaptive PMU Based Fault Detection/Location Technique for Transmission Lines, Part II: PMU Implementation and Performance Evaluation", IEEE Trans. on Power Delivery, vol. 15, no. 4, October 2000, pp. 1136-1146.

[13] "Alternative Transient Program Rule Book", Vol. 1, X. U. Leuven Center, July 1987.

\section{BIOGRAPHIES}

Joe-Air Jiang was born in Tainei, Taiwan, in 1963. He graduated from National Taipei University of Technology in 1983 and received M.S. and $\mathrm{Ph} . \mathrm{D}$. degrees in electrical engineering from National Taiwan University, Taipei, Taiwan in 1990 and 1999. From 1990 to 2001, he was with Private Kuang-Wu Institute of Technology and Commerce. Then he came to National Taiwan University where he is now assistant professor of bio-industrial mechatronics engineering. His area of interest is in computer relaying, mechatronics, and bio-effects of EM-wave.

Ching-Shan Chen was born in Taichung, Taiwan, in 1975. He received his B.S. degree in electrical engineering from National Taiwan University of Technology and Science in 1998. His M.S. degree in electrical engineering was received form National Taiwan University, Taipei, Taiwan in 2000. He is currently working toward his Ph.D degree in Electrical Engineering Department of National Taiwan University. At present, his interested research includes computer relaying and the application of artificial intelligence to power system protection.

Ping-Lin Fan was born in Taipei, Taiwan, on December 29,1961. He received the B.S. degree in electrical engineering and the M.S. degree in optical science from the National Central University, Chung-Li, Taiwan, in 1985 and 1987, respectively. He is currently working toward the Ph.D. 
degree. His research interests cover the design and application of mechatronics.

Chih-Wen Liu was born in Taiwan in 1964. He received the B.S. degree in Electrical Engineering from National Taiwan University in 1987, and M.S. and Ph.D. degrees in electrical engineering from Cornell University in 1992 and 1994. Since 1994, he has been with National Taiwan University, where he is associate professor of electrical engineering. He is a member of the IEEE and serves as a reviewer for IEEE Transactions on Circuits and Systems, Part I. His main research area is in application of computer technology to power system monitoring, operation, protection and control. His other research interests include GPS time transfer and chaotic dynamics and their application to system problems.

Rong-Seng Chang received the M.S. degree in laser and electro-optics from the Hebrew Univ. of Jerusalem and the Ph.D. degree from the Optical Sciences center, University of Arizona, in 1972 and 1982,respectively. He is a professor at the Institute of Optics Science, National Central University, Taiwan. His current research interests are in optical design, image processing, and biochip. 